Correction

\title{
Correction: Guo, Q.; et al. Comparison of in Situ and ex Situ Methods for Synthesis of Two-Photon Polymerization Polymer Nanocomposites. Polymers 2014, 6, 2037-2050
}

Qingchuan Guo ${ }^{1 *}$, Reza Ghadiri ${ }^{1}$, Thomas Weigel ${ }^{1}$, Andreas Aumann ${ }^{1}$, Evgeny L. Gurevich ${ }^{1}$, Cemal Esen ${ }^{1}$, Olaf Medenbach ${ }^{2}$, Wei Cheng ${ }^{3}$, Boris Chichkov ${ }^{3}$ and Andreas Ostendorf ${ }^{1}$

1 Department of mechanical Engineering, Ruhr-University Bochum, Universitätsstr. 150, 44801 Bochum, Germany; E-Mails: ghadiri@lat.rub.de (R.G.); weigel@lat.rub.de (T.W.); aumann@lat.rub.de (A.A.); gurevich@lat.rub.de (E.L.G.); esen@lat.rub.de (C.E.); andreas.ostendorf@rub.de (A.O.)

2 Department of Geology, Mineralogy and Geophysics, Ruhr-University Bochum, Universitätsstr. 150, 44801 Bochum, Germany; E-Mail: olaf.medenbach@rub.de

3 Laser Zentrum Hannover e. V., Hollerithallee 8, 30419 Hannover, Germany;

E-Mails: w.cheng@1zh.de (W.C.); b.chichkov@1zh.de (B.C.)

* Author to whom correspondence should be addressed; E-Mail: guo@lat.rub.de;

Tel.: +49-234-322-8488; Fax: +49-234-321-4259.

Received: 4 August 2014; Accepted: 7 August 2014 /

Published: 22 September 2014

The authors wish to make the following corrections to this paper [1]. In Figure 4, the unit of $\mathrm{CuKa}$ radiation is $\AA$, not $\mu \mathrm{m}$. The caption of Figure 4 should read: XRD patterns of pure $\mathrm{TiO}_{2}$ nanoparticles heat-treated at $80^{\circ} \mathrm{C}, 150{ }^{\circ} \mathrm{C}, 220^{\circ} \mathrm{C}$, and $250^{\circ} \mathrm{C}$ were obtained by using $\mathrm{CuK} \alpha$ radiation at $\lambda=1.5406 \AA$. 
Figure 4. $\mathrm{XRD}$ patterns of pure $\mathrm{TiO}_{2}$ nanoparticles heat-treated at $80{ }^{\circ} \mathrm{C}, 150{ }^{\circ} \mathrm{C}, 220{ }^{\circ} \mathrm{C}$, and $250{ }^{\circ} \mathrm{C}$ were obtained by using $\mathrm{CuK} \alpha$ radiation at $\lambda=1.5406 \AA$. (*) shows substrate Incubo peak.

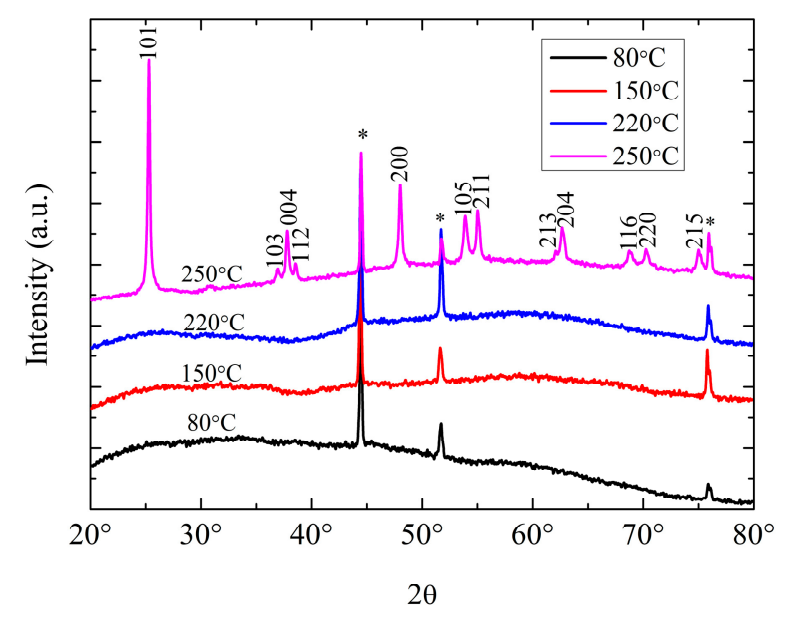

\section{Reference}

1. Guo, Q.; Ghadiri, R.; Weigel, T.; Aumann, A.; Gurevich, E.L.; Esen, C.; Medenbach, O.; Cheng, W.; Chichkov, B.; Ostendorf, A. Comparison of in Situ and ex Situ Methods for Synthesis of Two-Photon Polymerization Polymer Nanocomposites. Polymers 2014, 6, 2037-2050.

(C) 2014 by the authors; licensee MDPI, Basel, Switzerland. This article is an open access article distributed under the terms and conditions of the Creative Commons Attribution license (http://creativecommons.org/licenses/by/3.0/). 